$\begin{gathered}\text { Revista do Departamento de Geografia } \\ \text { Universidade de São Paulo } \\ \text { www.revistas.usp.br/rdg }\end{gathered}$
Volume Especial (2016)
ISSN 2236-2878

\title{
REFLEXÕES ACERCA DO SISTEMA CLIMA URBANO E SUA APLICABILIDADE: PRESSUPOSTOS TEÓRICO-METODOLÓGICOS E INOVAÇÕES TÉCNICAS
}

\author{
REFLECTIONS ON URBAN CLIMATE SYSTEM AND ITS APPLICABILITY: \\ THEORETICAL-METHODOLOGICAL ASSUMPTIONS AND TECHNICAL INNOVATIONS
}

\author{
José Carlos Ugeda Júnior \\ Universidade Federal de Mato Grosso \\ ugedajunior@gmail.com
}

Margarete Cristiane de Costa Trindade Amorim

Universidade Estadual Paulista Julho de Mesquita Filho

mccta@fct.unesp.br

Recebido (Received): 20/08/2016

Aceito (Accepted): 01/10/2016

10.11606/rdg.v0i0.119402

Resumo: Considerando que a proposta do Sistema Clima Urbano - SCU, Monteiro (1976), completou 40 anos, o presente trabalho visa desenvolver algumas reflexões sobre os seus pressupostos teórico-metodológicos, bem com sua aplicabilidade e os avanços técnicos verificados nas últimas décadas. As propostas do professor Carlos Augusto de Figueiredo Monteiro foram basilares para o desenvolvimento tanto da escola da climatologia dinâmica brasileira, quanto da escola da climatologia urbana brasileira. Essas propostas estão fundamentadas na revisão do conceito de clima de Max Sorre e Pierre Pédelaborde, bem como na Teoria Geral dos Sistemas de Ludwig Von Bertalanffy. A partir destas contribuições Monteiro, criou o conceito de Análise Rítmica em climatologia, além de introduzir o tratamento do clima a partir da perspectiva sistêmica. Ao se analisar a produção da climatologia urbana brasileira, percebe-se que a grande maioria dos trabalhos está pautada no Sistema Clima Urbano ou a ele fazem referência, o que demonstra que a aplicabilidade da proposta é plenamente atual e permite a compreensão das características climáticas das cidades. Do ponto de vista técnico, considera-se que houveram avanços significativos, que por sua vez permitiram uma compreensão mais detalhada do SCU, sobretudo em relação a sua dinâmica espacial e temporal.

Palavras-chave: Sistema clima urbano, Teoria, Método e técnica.

\begin{abstract}
Whereas the proposal of the Urban Climate System - UCS developed by Monteiro (1976), turned 40, this article aims to develop some reflections on their theoretical and methodological assumptions, as well as its applicability and technical progress achieved in recent decades. The importance of this proposal is recognized in the scientific community and has been the basis of what is called the Brazilian school of urban climatology. Both the rhythmic analysis, also proposed by Monteiro, as the urban climate system were based on the review of the concept of climate by Max Sorre and Pierre Pédelaborde and the General Theory of Systems by Ludwig Von Bertalanffy. From these contributions, Monteiro created the concept of Rhythmic Analysis in climatology and introduced the climate approach from the systemic perspective. When analyzing the production of urban Brazilian climatology, it is clear that the vast majority of the studies are guided on Urban Climate System or make reference to it, which demonstrates that the applicability of the proposal is present and allows the understanding of climate characteristics of the cities. From a technical point of view, it is considered that there have been significant advances in both the record of climate elements such as the different forms of spatial representation of those elements, which led to a more detailed understanding of the UCS, particularly regarding their spatial and temporal dynamics.
\end{abstract}

Keywords: Urban climate system, Theory, Method and technique. 


\title{
INTRODUÇÃO
}

O presente artigo visa desenvolver algumas reflexões sobre os pressupostos teórico-metodológicos balizadores do Sistema Clima Urbano - SCU - proposto por Monteiro (1976), bem com sua aplicabilidade e os avanços técnicos verificados nas últimas décadas, considerando que a proposta completou 40 anos.

Notadamente, Carlos Augusto de Figueiredo Monteiro, ao analisar as concepções teóricas de Maximilian Sorre e Pierre Pédelaborde, e adapta-la a circulação e a dinâmica atmosférica da América do Sul e do Brasil, criou o conceito de Análise Rítmica em climatologia, além de introduzir o tratamento do clima conforme a Teoria Geral dos Sistemas de Ludwig Von Bertalanffy (Mendonça e Danni-Oliveira, 2007). As suas proposições teórico-metodológicas e a enorme quantidade de estudos elaborados sob sua orientação acabaram por criar tanto uma "escola de climatologia urbana brasileira" (Mendonça, 1995) quanto uma "escola de climatologia dinâmica brasileira" (Zavattini, 1996).

Nesse sentido, a climatologia geográfica brasileira tem na obra de Monteiro um de seus pilares fundamentais. Diversos autores destacam as contribuições de Monteiro bem como suas possibilidades de aplicação, Sant'Anna Neto (2001), Zavattini (1998, 2000), Mendonça e Danni-Oliveira (2007), Barros (2009), Ely (2006), Amorim (2000), dentre outros.

\begin{abstract}
A climatologia é um dos ramos da Geografia Física: ela estuda as características da atmosfera em contato com a superfície terrestre e a distribuição espacial dessas características. Sua elaboração coloca, pois, o problema preliminar que acontece desde que se aborde qualquer compartimento da geografia, o problema das relações com as outras ciências. Em nome da natureza, dos fenômenos que ela abrange, a climatologia tira seus recursos essenciais da meteorologia. Certamente ela se apoia também em outras disciplinas da Geografia Física (o relevo, a natureza dos solos, a hidrografia, exercem influências no clima) e na Geografia Biológica e Geografia Humana (influência do meio vegetal e das cidades). Mas a essência dos fenômenos reside na atmosfera. É uma evidência impossível de não se reconhecer. (PÉDELABORDE, 1970, p.5, tradução nossa)
\end{abstract}

Dessa forma, a climatologia, além de um campo disciplinar e científico, torna-se um instrumento de síntese, na medida em que para se compreender os fenômenos climáticos integralmente, é necessário recorrer à composição e dinâmica da atmosfera, e também a sua interação com a superfície, o que envolve não apenas as características físicas do meio, mas também os elementos socialmente construídos, as formas de construção, e também o jogo de interesses por traz da forma como as sociedades materializam seu modo de vida no espaço através da técnica. Para tanto, se faz necessário definir claramente o conceito de clima ao qual se faz referência. A primeira contribuição apresentada aqui é a de Julius Hann, (1883, p.1, tradução nossa): "o clima é o conjunto dos fenômenos meteorológicos que caracterizam o estado médio da atmosfera em um ponto da superfície terrestre".

Sorre (1951, 1955), Pédelaborde (1970), Monteiro (1976, 1991), entre outros, criticaram essa definição, pois o estado médio da atmosfera é uma abstração que não permite visualizar os extremos. O clima passa a ser caracterizado pela média e não pela ocorrência de eventos atmosféricos. Por outro lado, essa definição também é muito criticada por representar um estado estático e artificial da atmosfera e não menciona o desenvolvimento dos fenômenos atmosféricos ao longo do tempo, não considerando, portanto, o ritmo, que é um elemento fundamental para a compreensão do clima.

Para Maximilien Sorre (1955, p.14, tradução nossa): "O clima é definido pela série de estados atmosféricos sobre um lugar em sua sucessão habitual." A definição de Sorre, além de contemplar a dinâmica da atmosfera, traz também a ideia de ritmo.

Para Pédelaborde (1970, p.19, tradução nossa): "O clima, assim como o tempo, resulta de uma combinação de elementos. Mas é a combinação das tendências dominantes e permanentes (isto é, dos elementos gerais) da atmosfera sobre um lugar". A definição de Pédelaborde, embora contemporânea à de Sorre, define o clima em função da combinação das tendências dominantes e permanentes da atmosfera de um dado local. Entretanto, "as tendências dominantes e permanentes" por si só, não contemplam a ideia de ritmo, nítida na definição de Sorre. 
Tanto a definição de Sorre, como a de Pédelaborde, rompem com o entendimento do clima através da média dos tipos de tempo, entretanto Monteiro (1976, p. 21) destaca que Sorre:

[...] propôs uma mudança de paradigma para a pesquisa climatológica. [...] a nova perspectiva é dinâmica (série e sucessão) e está baseada em uma propriedade intensiva da atmosfera - a própria ideia de tempo meteorológico essencialmente associativa. Parece-me que não há dúvida de que o paradigma novo é o ritmo em substituição à média dos elementos discretamente dissociados à atmosfera e expressos como meras propriedades extensivas. (MONTEIRO, 1976, p.21)

Como destaca Monteiro, Sorre foi o responsável pela mudança de paradigma do entendimento do clima e por consequência da climatologia, sendo que a ruptura com o paradigma anterior veio através da inserção da noção de ritmo. Monteiro afirma ainda que:

A proposta de Sorre não se reveste da pompa de uma teoria científica explicitada e formulada nos moldes lógicos e habituais da ciência. Creio, porém, não ser exorbitância estabelecer cautelosa ou tímida analogia entre a redefinição do conceito de clima e as regras que devem nortear-lhe a pesquisa como, pelo menos, um embrião de teoria. (MONTEIRO, 1976, p.24)

Dessa forma, é notória a contribuição de Sorre para o avanço do estudo científico do clima, entretanto, o mesmo autor não apresenta um referencial metodológico para tal estudo. Ou como coloca Monteiro, Sorre cria, através da revisão do conceito de clima, a base ou o embrião para uma nova teoria do clima.

Essa base lançada por Sorre motivou Monteiro, a fundamentar um corpo teórico e metodológico para o estudo do clima através da análise rítmica, além, de revolucionar o estudo do clima urbano através do Sistema Clima Urbano. O próprio Monteiro afirma:

Eu parti da importante revisão conceitual que Max SORRE fez do clima na geografia. Eu não poderia ter seguido uma trajetória produzida por ele pelo simples fato de que o eminente geógrafo jamais realizou, ou pelo menos publicou um trabalho de climatologia. (MONTEIRO, 1991, p. 37)

Dessa forma, destaca-se a importância da obra de Monteiro para o desenvolvimento da climatologia, ao compor um corpo teórico acompanhando de todo instrumental metodológico para o estudo do clima de maneira geral e do clima urbano de maneira específica, partindo do conceito de clima proposto por Max Sorre. O ritmo representou o novo paradigma conceitual, em substituição ao uso das médias e chegou-se a climatologia dinâmica que tem como propósito entender o clima através das características da realidade, e não mais, através de abstrações matemáticas, que em diversos momentos nortearam as pesquisas climáticas.

Sendo o clima urbano entendido como o clima de um dado espaço associado ao seu processo de urbanização, que expressa as condições atmosférica resultantes da interação de diferentes escalas climáticas e de superfície, (MONTEIRO, 1976), a observação do clima local deve ser acompanhada da análise das características geoambientais, características físicas do meio geográfico, assim como, das características do processo de urbanização dos espaços a serem estudados, pois, dessa forma é possível identificar quais as alterações climáticas e suas magnitudes, além de relacioná-las às ações sociais.

Como coloca Sorre:

A noção de clima refere-se principalmente, a um lugar e a uma estação. Abordagem comum justificada pela observação científica. $\mathrm{O}$ conjunto das variações atmosféricas que nossos sentidos registram, difere de um lugar para outro muito rapidamente e cada lugar apresenta uma individualidade original, por vezes, individualmente irredutível. Uma pequena diferença de altitude, a orientação das vertentes em uma mesma colina, a mudança da vertente para o planalto, as horas de insolação, a turbulência do ar, temperatura, chuvas, tudo muda. (SORRE, 1955, p.14-15, tradução nossa) 
Além de todos os fatores elencados por Sorre, se adiciona mais um: a produção do espaço urbano, que, assim como outros fatores, também não ocorre de maneira homogênea em todas as cidades. A intensidade da ocupação do solo, o nível de verticalização, a vegetação urbana, os tipos de materiais construtivos, o uso do solo, a intensidade do tráfego, enfim, todos os elementos que são inerentes ao espaço urbano se diferenciam, não só entre uma cidade e outra, mas também entre os bairros da mesma cidade, e entre a cidade e o campo.

Em relação aos estudos desenvolvidos no âmbito da climatologia urbana brasileira, foco principal de análise desse artigo, a grande maioria dos trabalhos está pautada no Sistema Clima Urbano ou a ele faz referência. Sendo assim, o presente artigo tem como proposta refletir sobre os pressupostos teóricometodológicos balizadores do SCU e posteriormente compreender como as inovações técnicas têm influenciado os trabalhos realizados atualmente.

\section{PRESSUPOSTOS TEÓRICO-METODOLÓGICOS}

Monteiro (1976, p.57), organizou uma síntese feita por Landsberg ${ }^{1}$ para iniciar a caracterização do clima urbano:

a) O clima urbano é a modificação substancial de um clima local, não sendo possível ainda decidir sobre o ponto de concentração populacional ou densidade de edificações em que essa notável mudança principia;

b) Admite-se que o desenvolvimento urbano tende a acentuar ou eliminar as diferenças causadas pela posição ou sítio;

c) Da comparação entre a cidade e o campo circundante emergiram os seguintes fatos fundamentais;

c1) A cidade modifica o clima através de alterações em superfície;

c2) A cidade produz um aumento de calor, complementada por modificações na ventilação na umidade e até na precipitação, que tende a ser mais acentuada;

c3) A maior influência manifesta-se através da alteração na própria composição da atmosfera, atingindo condições adversas na maioria dos casos. A poluição atmosférica representa, no presente, o problema básico da climatologia das modernas cidades industrializadas. (LANDSBERG apud MONTEIRO, 1976, p.57)

Em relação ao ponto de concentração ou densidade de ocupação, no qual, a modificação substancial do clima local surge, formando o clima urbano, tradicionalmente, os estudos consideraram as grandes cidades e regiões metropolitanas, e os resultados apresentavam variações térmicas de $3^{\circ} \mathrm{C}$ a $10^{\circ} \mathrm{C}$. Entretanto, com o avanço das pesquisas, além, dos equipamentos utilizados, as cidades de médio e pequeno porte também passaram a ser analisadas, sendo que, os resultados demonstravam que cidades pequenas, com população inferior a cinquenta mil habitantes, também apresentavam modificações substanciais, notadamente no campo térmico e higrométrico, de magnitudes semelhantes às observadas nos grandes centros.

Além das diferenças climáticas causadas pela posição e pelo sítio onde são construídas as cidades, deve-se admitir que a produção do espaço urbano, tem a capacidade de acentuar ou eliminar as alterações climáticas causadas pela própria urbanização, de modo que, o planejamento urbano, adequado ao meio em que a cidade está inserida pode ser uma ferramenta capaz de minimizar senão solucionar as alterações climáticas encontradas nos ambientes urbanos. Entretanto, se faz necessário ressaltar que tais processos de planejamento devem contemplar os elementos ambientais urbanos.

Acredita-se que as alterações climáticas que configuram o clima urbano surgem devido à forma como a cidade é construída, e mais ainda, devido aos interesses sociais e econômicos que direcionam a produção do espaço urbano. O clima urbano surge na própria organização cultural de nossas sociedades, que elegem diversas premissas (morais, sociais, econômicas e técnicas) mais importantes do que a qualidade de vida. Mesmo que, ainda exista um longo caminho de pesquisa para que todos os argumentos necessários para a consolidação dessa afirmação sejam alcançados, ela se manifesta de forma cada vez mais evidente. Admite-se, entretanto, que a partir do atual modelo de planejamento e gestão urbana, as soluções para os problemas climáticos das cidades se tornam cada vez mais difíceis e onerosas.

${ }^{1}$ LANDSBERG, H.E. The climate of towns. In THOMAS, W. E., ec. Mans role in changing the face of earth. P. 584606. 
Deve-se reconhecer também, que a existência de um clima urbano específico não é, necessariamente negativa. Sob certas condições climáticas como as polares, temperadas e desérticas, alterações intencionais causadas pela construção da cidade, podem minimizar os impactos causados à qualidade de vida. Sendo possível, por exemplo, diminuir a velocidade do vento e alcançar temperaturas mais confortáveis. Contudo, todas essas modificações devem ocorrer a partir de uma intencionalidade e de processos de planejamento e gestão urbana adequados.

No Brasil, geralmente a existência do clima urbano representa problemas à qualidade de vida da população. Isso porque, as alterações climáticas observadas nas cidades brasileiras não são intencionais, principalmente devido ao fato de que o planejamento urbano, historicamente praticado, não é realizado a partir de premissas sociais, econômicas e ambientais, e sim, quase que exclusivamente, a partir de premissas econômicas. De modo geral, as cidades crescem sem levar em consideração as características do meio ao qual estão inseridas, o que acaba por levar a queda na qualidade ambiental.

Compreender de maneira integral o meio em que as cidades estão inseridas, é o primeiro passo para que os processos de planejamento urbano considerem as características ambientais no momento da tomada de decisões. Especificamente, em relação ao clima urbano, se torna necessário fazer referência aos dez enunciados propostos por Monteiro, (1976, p.95 - 102), com o objetivo de se aprofundar o conhecimento deste importante componente do ambiente urbano.

1. O clima urbano é o clima de um dado espaço terrestre e sua urbanização. (MONTEIRO, 1976, p.95)

O primeiro enunciado deixa claro que, a existência de um clima urbano específico não se restringe a determinados padrões urbanos, tanto em magnitude como em densidade, mas está nitidamente relacionado com o tipo, ou melhor, com a forma como se dão os processos de urbanização. Notadamente, uma cidade que se desenvolve de maneira adequada com o meio que está inserida, respeitando padrões de densidade, de vegetação urbana e controlando a emissão de poluentes pode, em tese, minimizar ou até mesmo evitar as alterações climáticas. Entretanto, cidades, mesmo que de pequeno porte, que crescem sem levar em consideração as características ambientais do sitio urbano, estão, inevitavelmente, caminhando para alterações climáticas capazes de gerar um clima urbano específico.

2. O espaço urbanizado, que se identifica a partir do sítio, constitui o núcleo do sistema que mantêm relações íntimas com o ambiente regional imediato em que se insere. (MONTEIRO, 1976, p.96)

Assim, o segundo enunciado explicita que, as relações entre o fenômeno urbano e o clima estão sujeitas a diversas escalas, tanto verticais quanto horizontais, de modo que, o clima local está inserido no regional e este no zonal e, as influências da circulação atmosférica estão diretamente relacionadas com os elementos locais do espaço urbano, assim como, as alterações na composição da atmosfera urbana podem levar a modificações na escala vertical, como, por exemplo, o fenômeno de inversão térmica.

Além disso, a compartimentação climática do espaço urbano, pode ser tão intrincada quanto à complexidade desses espaços, de modo que, unidades diferenciadas da paisagem dentro da mesma cidade, têm potencial para gerar diferenças térmicas e higrométricas interurbanas significativas.

3. O SCU importa energia através de seu ambiente, é sede de uma sucessão de eventos que articulam diferenças de estados, mudanças e transformações internas, a ponto de gerar produtos que se incorporam ao núcleo e/ou são exportados para o ambiente, configurando-se como um todo de organização complexa que se pode enquadrar na categoria dos sistemas abertos. (MONTEIRO, 1976, p.96)

O SCU é considerado um sistema aberto, devido à intensa troca de matéria e energia, entre os ambientes urbanos e o meio ao qual estão inseridos. Apesar de não existir sistema fechado, na acepção exata do termo, alguns autores o consideram como àquele que tem um pequeno intercâmbio com o ambiente. Já os sistemas abertos, não podem viver em isolamento, eles se mantêm através de um contínuo fluxo de entradas e saídas, nunca estando em um estado de perfeito equilíbrio.

A relação entre o SCU - por ser um sistema aberto - e o meio é constante, ou seja, eles estão interrelacionados, tendo em vista que as entradas de um sistema partem do ambiente e retornam através das saídas geradas pelo processamento. O sistema recebe influências do ambiente através de entradas e o influencia através de saídas. Entretanto, as alterações exercidas pelo sistema podem retornar ao próprio 
sistema através da retroalimentação. Assim, a viabilidade de um sistema, depende da sua capacidade de adaptar-se, mudar e responder às exigências e demandas do ambiente externo.

Esse raciocínio pode ser realizado com a sociedade no centro da análise, pois ela está inserida no SCU, e assim, como o ambiente, as ações sociais geram entradas de matéria e energia, que podem retornam à própria sociedade. Entretanto, por ser um sistema aberto, ações iniciadas pela ação social podem ser retroalimentadas, fato que pode gerar sérios impactos ao equilíbrio do sistema. Fica a questão: até que ponto a sociedade será capaz de se adaptar as mudanças identificadas no SCU? Ou melhor, qual a magnitude de riscos que a sociedade está propensa a aceitar?

Todas estas questões devem ser levadas em consideração, pois como colocou o filósofo Inglês Herbert Spencer, "um organismo social assemelha-se a um organismo individual nos seguintes traços essenciais":

$\checkmark$ No crescimento;

$\checkmark$ No fato de se tornar mais complexo à medida que cresce;

$\checkmark$ No fato de que, tornando-se mais complexo, suas partes exigem uma crescente interdependência;

$\checkmark$ Porque sua vida tem imensa extensão comparada com a vida de suas unidades componentes;

$\checkmark$ Porque em ambos os casos há crescente integração acompanhada por crescente heterogeneidade.

Dessa forma, tanto a sociedade quanto o SCU são mais duradouros do que a vida humana, e que levar em conta as questões acima colocadas, implica ampliar o tempo de retorno para longos prazos, sendo a irreversibilidade das perdas, um elemento importante que, via de regra, não é considerado nos processos de planejamento. Nesse sentido, faz-se necessário compreender que no processo de produção do espaço urbano, pautado por intervenções sociais cada vez mais estruturais, tecnificadas e intensificadas, a sociedade perdeu de vista a noção de interdependência e complexidade na relação sociedade natureza. Cada vez mais deslumbra-se pelo novo, pelo moderno. Ou como aponta Pádua;

De toda forma, essa contradição entre o otimismo progressista da modernidade e o pessimismo potencial da crítica ecológica, que alguns preferem chamar de "realismo ecológico", continua presente no debate intelectual e na cena política do mundo contemporâneo. O discurso pode ser incluído, dessa forma, nos primórdios do enfrentamento teórico de um dos dilemas básicos da humanidade atual. (PÁDUA, 2004, p.119)

Fica evidente que a prática social ainda não absorveu a complexidade da relação sociedade natureza. Seja pela ação direta dos agentes produtores do espaço urbano, que não consideram as características do ambiente em suas ações, seja pela aceitação social dessas práticas.

4. As entradas de energia no SCU são de natureza térmica (oriundas da fonte primaria de energia da terra - o Sol), implicando componentes dinâmicas inequívocas determinadas pela circulação atmosférica, e decisivas para a componente hídrica englobada nesse conjunto. (MONTEIRO, 1976, p.97)

Dessa maneira, como coloca o próprio autor: "[...] o organismo urbano do ponto de vista da radiação, constitui a própria superfície terrestre no contexto do SCU." Portanto, a forma urbana, os materiais construtivos utilizados, a densidade de ocupação, a verticalização, e o uso do solo, vão alterar os fluxos normais de reflexão, absorção e armazenamento de energia, alterando o ritmo natural de ganho e perda de calor, gerando por fim, anomalias térmicas e higrométricas conhecidas como ilhas de calor, ilhas frescas, ilhas úmidas e ilhas secas.

Considerando que é a radiação de ondas longas, emitida pela superfície (no caso do SCU, a própria cidade) que aquece o ar, a atmosfera urbana está sujeita aos reflexos de todo o calor armazenado pelos materiais construtivos, que alteram inclusive, o ritmo de ganho e perda de energia, gerando noites mais quentes.

As modificações no balanço de radiação, geradas pela cidade alteram a inércia térmica urbana, causando sua diminuição se comparada inércia térmica do entorno rural, isso ocorre, principalmente, através da ampliação da densidade de ocupação dos espaços urbanos, pela diferença de calor específico existente 
entre os materiais naturais e os materiais construtivos e, principalmente, pela menor capacidade térmica desses materiais.

Se na mecânica a inércia é considerada como a força que limita a aceleração de um objeto, a inércia térmica pode ser entendida, por analogia, como a força que limita o aquecimento de determinada superfície, sendo que, quanto maior for à inércia térmica, menor será sua variação de temperatura.

O calor específico é entendido, como a variação da temperatura de determinado material ao receber determinada quantidade de energia. Ela é constante para cada material em cada um dos três estados físicos da matéria. Portanto, a substituição de materiais naturais com menor calor específico, por materiais construtivos com maior calor específico, certamente, irá gerar maior aquecimento da superfície.

A capacidade térmica é entendida, como a quantidade de energia necessária para que determinada material apresente a elevação de um grau em sua temperatura. Portanto, quanto menor for a capacidade térmica, menor será a quantidade de energia necessária para que a superfície apresente elevação de um grau na temperatura. De modo geral, os materiais construtivos urbanos têm menor capacidade térmica se comparados aos elementos naturais que compõem os espaços rurais. Portanto, a mesma quantidade de energia irá causar maior aquecimento na superfície urbana se comparada à superfície rural, salvo, em casos que exista solo exposto na zona rural. O solo exposto tem capacidade térmica menor e calor específico maior do que os observados nos materiais construtivos. Assim, áreas de solo revolvido para o plantio, ou longos períodos de estiagem têm a capacidade de causar maior aquecimento da superfície rural se comparada à urbana. Apesar dessa relação ser possível ela não é habitual.

Fica claro que, a alteração do balanço de energia identificada nas cidades, tem alta capacidade de provocar alterações térmicas positivas nos espaços urbanos.

As alterações higrométricas provocadas pela urbanização potencializam o aquecimento da superfície da cidade, principalmente, em função da diminuição da umidade nos espaços urbanos, que ocorre, devido à impermeabilização do solo, à retirada da vegetação e à canalização fechada dos corpos d' água. A urbanização provoca a diminuição da evaporação e da evapotranspiração, o que reduz a perda de energia através da transformação do calor sensível em calor latente.

A transformação da água do estado líquido para o estado gasoso, consome energia na forma de calor sensível e a transforma em calor latente, gerando queda na temperatura. Como na cidade a superfície impermeabilizada não retém água, a energia que seria transformada em calor latente acaba não sendo utilizada, ficando disponível na forma de calor sensível, o que intensifica o aquecimento das áreas urbanas.

Ressalta-se que a complexidade do SCU, principalmente no tocante às inter-relações existentes entre os elementos do sistema e os mecanismos de retroalimentação, são capazes de intensificar as alterações causadas pela ação social, levando o SCU a um novo estado de equilíbrio dinâmico, tendo capacidade de interferir na qualidade de vida urbana.

5. A avaliação dessa entrada de energia no SCU deve ser observada tanto em termos quantitativos como especialmente em relação ao seu modo de transmissão. (MONTEIRO, 1976, p.98)

Assim como o paradigma rítmico transforma o entendimento do clima, a análise do modo como a energia transita dentro do SCU, é fundamental para compreendê-lo, uma vez que, esse trânsito pressupõe um ritmo, e as alterações na forma e nos tipos de materiais causadas pela urbanização vão alterar com maior ou menor intensidade todo o modo e o ritmo, como a energia é transmitida no SCU. Essa alteração no trânsito da energia, inevitavelmente irá causar alterações no ritmo climático, de maneira especial, em relação ao ganho e perda de calor, que passa então a se adaptar às propriedades térmicas dos materiais construtivos utilizados.

Deve-se destacar o processo de retroalimentação associado à poluição urbana e as partículas em suspensão, pois, elas podem elevar a absorção e a reflexão da energia, aumentando consequentemente, o tempo necessário para que o SCU dissipe essa energia. Esses fatores são responsáveis para que a máxima expressão das ilhas de calor ocorra no período noturno. 
6. A estrutura interna do SCU não pode ser definida pela simples superposição ou adição de suas partes (compartimentação ecológica, morfológica, ou funcional urbana), mas somente por meio da íntima conexão entre elas. (MONTEIRO, 1976, p.99)

Os sistemas abertos são compostos por seus elementos (partes) e a relação entre eles, ou seja, as relações são os laços que ligam os elementos entre si. A caracterização dos sistemas dá-se pelos seguintes parâmetros:

$\checkmark$ Entrada ou insumo - é a força de arranque de um sistema, permite a operação do sistema;

$\checkmark$ Processamento ou transformação - fenômeno que produz mudança; converte entradas em saídas;

$\checkmark$ Saída ou resultado - finalidade para qual se reuniram elementos e relações do sistema;

$\checkmark$ Retroação ou retroalimentação - função que visa comparar a saída a determinados padrões estabelecidos. Visa manter ou aperfeiçoar o desempenho do processo;

$\checkmark$ Ambiente - é o meio que envolve o sistema.

Fica evidente nesse momento, a importância de se romper com a concepção positivista da natureza (CASSETI, 1991, p.11), sendo que, os elementos naturais e sociais, além dos demais componentes do SCU, se relacionam diretamente, ao passo que, se através do positivismo é possível entender que a natureza humana demonstra o seu domínio sobre as leis da natureza, estar-se-á retirando o homem (parte do sistema) do SCU e o sobrepondo a ele, fato que, inegavelmente, trará equívocos interpretativos.

Deve ficar claro que, os elementos e todas as partes do SCU formam um todo indissociável, e que sua interpretação pressupõe compreender as entradas, transformações e saídas de energia, além de, sua retroalimentação, elementos que devem estar relacionados com o meio onde o SCU está inserido, além de se considerar as ações sociais e sua capacidade de modificar e complicar as relações existentes.

7. O conjunto-produto do SCU pressupõe vários elementos que caracterizam a participação urbana no desempenho do sistema. Sendo variada e heterogênea essa produção, faz-se mister uma simplificação classificatória que deve ser constituída através de canais de percepção humana. (MONTEIRO, 1976, p.100)

Monteiro completa ainda que a poluição do ar, ilhas de calor, inundações no espaço urbano, dentre outras formas, assumem destaque nos climas urbanos, refletindo, com isso, peculiaridades do clima da cidade. Alguns processos podem ocorrer na natureza sem a presença do homem, como as enchentes ou a solifluxão ${ }^{2}$, entretanto, é a forma de atuação social que intensifica tais processos, gerando os impactos.

Destaca-se que é através da avaliação e percepção humana e da avaliação social e coletiva que uma sociedade cria e admite padrões de valores e de problemas aceitáveis e não aceitáveis, e que, portanto, a configuração dos problemas passa não só pela ação social, mas também pelo seu julgamento. Para tanto, Monteiro propõe três canais de percepção humana, com o objetivo de enquadrar os elementos climáticos em uma estrutura analítica:

a) Conforto Térmico - Englobando os componentes termodinâmicos que em suas relações, se expressam através do calor, ventilação e umidade nos referenciais básicos a esta noção. É um filtro perceptivo bastante significativo, pois afeta a todos permanentemente. Constitui, seja na climatologia médica, seja na tecnologia habitacional, assunto de investigação de importância crescente.

b) Qualidade do $\mathrm{Ar}$ - A poluição é um dos males do século, e talvez aquele que, por seus efeitos mais dramáticos, atraia mais atenção. Associada às outras formas de poluição (água, solo, etc.), a dor ar é uma das mais decisivas na qualidade ambiente urbana.

c) Meteoros do Impacto - Aqui estão agrupadas todas aquelas formas meteóricas, hídricas (chuva, neve, nevoeiros), mecânicas, (tornados) e elétricas (tempestades) que, assumindo, eventualmente, manifestações de intensidade, são capazes de causar impacto na vida da cidade, perturbando-a ou desorganizando-lhe a circulação e serviços. (MONTEIRO, 1976, p.100)

\footnotetext{
${ }^{2}$ Movimento de escorregamento lento de terrenos, fenômeno frequente, sobretudo em terrenos argilosos, que pode movimentar massas enormes de rochas e originar acidentes desastrosos, provocado, em geral, pela entrada de água, que os tornam excessivamente plásticos e tendem a deslocar-se, pela ação da gravidade, para lugares mais baixos.
} 
Através dos três canais de percepção, é possível organizar todos os elementos climáticos para análises em conjunto dos fatores termodinâmicos, físico-químicos e hídricos, de modo que, como já dito, é a percepção humana associada ao sistema de valores de cada sociedade, que dará o devido tom aos elementos climáticos, avaliando o que é, e o que não é aceitável.

8. A natureza urbana do SCU implica em condições especiais de dinamismo interno consoante ao processo evolutivo do crescimento e desenvolvimento urbano, uma vez que várias tendências ou expressões formais de estrutura se sucedem ao longo do processo de urbanização. (MONTEIRO, 1976, p.100)

Evidentemente, as inter-relações entre o natural e o social dentro do SCU, são tão diversas quanto são diversificadas às características de cada processo de urbanização. As cidades não se desenvolvem de maneira homogênea, como se observa na diferença entre a produção do espaço urbano dos países desenvolvidos para os países em desenvolvimento. Nesses últimos, a urbanização ocorre tardiamente e com um ritmo altamente acelerado, fato que pode intensificar os impactos ao ambiente e reduzir a qualidade de vida. Entretanto, mesmo dentro desses dois grupos de países, as cidades não se desenvolvem da mesma maneira.

A título de exemplo, em linhas gerais, as cidades brasileiras, salvo raras exceções, passaram por expansão territorial desprovida de processos de planejamento urbano, principalmente, aqueles capazes de prever situações de longo prazo. Deste modo, se observa um crescimento desordenado em um número significativo de cidades. A gestão urbana, na maioria das vezes, se restringe à correção dos problemas gerados pelo crescimento desordenado. Associando-se a ausência de planejamento à descontinuidade administrativa, verifica-se que, as cidades se desenvolvem de maneira caótica, sem seguir um plano estratégico. As motivações para tal crescimento são quase que exclusivamente econômicas, e o interesse financeiro, visando à maximização do lucro, é o que dá as diretrizes básicas para o crescimento urbano sem se considerar as consequências dessa forma de agir.

Sendo o interesse econômico variável, em cada cidade, em cada momento histórico, e em cada grupo que forma a teia de relações de interesse e poder, as cidades também crescem de forma diversificada, mesmo que, muitos problemas sejam comuns, a variação de intensidade, de frequência de ocorrência, e da população atingida confere, à cada cidade, particularidades e especificidades próprias, com maior ou menor grau de risco e de impactos à qualidade ambiental e a qualidade de vida da população.

Neste contexto, fica claro, que para se compreender profundamente o SCU, deve-se analisar minuciosamente, como ocorre o processo de urbanização e o crescimento urbano em cada localidade estudada, esclarecendo suas particularidades e possíveis consequências.

9. O SCU é admitido como passível de auto regulação, função essa conferida ao elemento homem urbano que, na medida em que o conhece é capaz de detectar suas disfunções e, pode, através de seu poder de decisão, intervir e adaptar o funcionamento do mesmo, recorrendo à dispositivos de reciclagem e/ou circuitos de retroalimentação capazes de conduzir o seu desenvolvimento e crescimento seguindo metas preestabelecidas. (MONTEIRO, 1976, p.101)

Os problemas gerados no processo de produção do espaço urbano, que visa apenas o interesse econômico, são graves e de inúmeras ordens. Ressalta-se que, faz-se necessário a identificação de metodologias capazes de contemplar os elementos da natureza nos processos de planejamento, com a finalidade de minimizar os impactos ambientais inerentes ao processo de urbanização, assim como maximizar a qualidade ambiental urbana e em última análise a qualidade de vida da população residente nas cidades.

Esse processo ocorrerá, efetivamente, quando os diversos atores sociais, ou a população de uma forma mais geral, se sensibilizarem para o fato de que a produção do espaço urbano não deve ser direcionada por interesses de um grupo restrito, pois, as consequências e erros urbanísticos afetam a grande maioria da população.

É imprescindível que a expansão da cidade ocorra de forma participativa, sendo que, a população deve ser consultada através de audiências públicas. Além da construção participativa da cidade, é necessária a efetivação de um corpo técnico multidisciplinar dentro das secretarias de planejamento. O caráter técnico e participativo do planejamento e da gestão urbana deve sobrepor-se aos interesses econômicos. 
Entende-se aqui, que essa é a única forma para se atingir a auto regulação dentro do SCU, e essa forma passa, por desmontar a trama de interesses e o jogo de poder por traz do crescimento urbano. Ela requer inevitavelmente solução técnicas, debate acerca dos interesses econômicos e participação social.

10. Pela possibilidade de interferência auto reguladora, acrescentam-se ao SCU, como sistema aberto, aquelas propriedades de entropia negativa pela sua própria capacidade de especialização dentro do crescimento através de processos adaptativos, podendo ser qualificados, assim, como um sistema morfogenético. (MONTEIRO, 1976, p. 102)

Através da segunda lei da termodinâmica, a entropia pode ser entendida como o estado de desordem ou desorganização de um sistema, isso porque, o trabalho pode ser completamente convertido em calor, mas o calor, não pode ser completamente convertido em trabalho. Dessa forma, faz-se necessário existir uma medida da desordem, ou seja, da quantidade de energia que passa a um estado de desorganização que não poderia mais ser prontamente utilizada. Assim, a entropia crescente levaria a desorganização crescente. Portanto, como no universo, a energia está constantemente passando de um estado organizado para um estado de desorganização, a sua entropia tende a crescer. Em termos práticos, tudo que se constrói tende a se destruir, a se desfazer.

Se a entropia, é a tendência a qual o universo está sujeito pela transformação constante de energia em estado organizado para estados desorganizados, surge também o conceito de entropia negativa, que seria o inverso da segunda lei da termodinâmica, ou seja, o suprimento de informações e ações adicionais para proporcionar integração e crescente organização no e do sistema. Se a entropia negativa não é possível através das leis da física teórica, ela pode ser concebida de maneira abstrata a partir da metafísica, principalmente, através das leis que regem sistemas menores, como o SCU, pois são, em essência, passíveis de interferência e auto regulação, através da ação antrópica, o que não é possível para as leis que regem o universo.

Pesquisas recentes no campo da biologia apontam para uma ordem organizadora da vida. Alterando a escala da microbiologia para a escala social, qual seria a força capaz de garantir homeostasia ao SCU? Acredita-se que, na acepção tradicional da palavra, ou seja, tendência do sistema em permanecer estático ou em equilíbrio, mantendo seu status quo interno, é aceitável que, não possa existir homeostasia no SCU. Entretanto, se entendermos homeostasia como sendo o equilíbrio dinâmico, obtido através da auto regulação, ou seja, através do autocontrole e da capacidade que tem o sistema de manter certas variáveis dentro de limites; obtidos através de mecanismos de feedback (retorno), é perfeitamente possível admitir que a ação social pode vir a ser a força capaz de garantir tal estado de equilíbrio dinâmico dentro do SCU.

Contudo, para que a ação social seja capaz de garantir entropia negativa ao SCU, é necessário um amplo processo de adaptabilidade, ou seja, faz-se necessário a mudança na organização do sistema para que se consiga um novo e diferente estado de equilíbrio com o ambiente. Assim, a mudança aqui colocada é claramente a mudança da forma como as sociedades têm historicamente se organizando e se relacionado com a natureza. Através do atual modelo de organização social, bem como das bases de nosso sistema de produção, o capitalismo - é difícil admitir que os seres humanos seriam capazes de abrir mão de lucros mais elevados em função de benefícios coletivos e de uma melhoria na qualidade de vida.

Ou como coloca Monteiro:

Pela sua tendência natural, estaria fadado a constituir um sistema organísmico à procura de equilíbrio homeostático. Pelo crescimento desordenado da urbanização, isso dificilmente seria obtido; e o sistema, agravado pela sobrecarga de produtos nocivos, viria, fatalmente, a entrar em entropia. Nada impede, contudo, que o homem urbano interfira, conscientemente, no sentido de elaborar as reciclagens necessárias e conduzir o crescimento urbano, no sentido da adaptação progressiva às metas de crescimento harmônico. [...] Creio que será mais otimista pensar nessa conscientização uma vez que não será nada realista pensar em que o homem iria sustar o crescimento urbano, a industrialização, a circulação de veículos para assegurar um hipotético equilíbrio ecológico e manter os padrões de qualidade de vida em níveis aceitáveis. (MONTEIRO, 1976, p. 102) 
Diante do exposto, acredita-se que fica claro a fundamentação teórica do Sistema Clima Urbano, que foi construído a partir da Teoria Geral dos Sistemas, que segundo Monteiro (2003 p.16) traz a "possibilidade alternativa de usar tanto o método indutivo quando o dedutivo". A colocação de Monteiro deixa claro que, dentro da perspectiva sistêmica, é possível tecer análises tanto através do raciocínio lógico dedutivo quanto com o indutivo, sendo possível entender os fenômenos do clima urbano tanto partindo de elementos particulares para se chegar a conclusões generalizadas sobre a realidade urbana, como também partindo de premissas gerais para chegar às conclusões específicas.

Assim, acredita-se que a aplicabilidade da proposta é plenamente atual e permite a compreensão das características climáticas das cidades, mesmo 40 anos após sua publicação. Contudo, do ponto de vista técnico, ocorreram diversas alterações que têm permitido novas possibilidades de entendimento do clima urbano. Vejamos algumas delas.

\section{INOVAÇÕES TÉCNICAS E REPRESENTAÇÕES ESPACIAIS}

Se do ponto de vista teórico-metodológico não houveram significativas alterações e o SCU permanece essencialmente aquilo que foi proposto por Monteiro (1976), já do ponto de vista técnico e das representações espaciais, diversas alterações se processaram nesses 40 anos. Destaca-se a evolução dos instrumentos e a popularização dos registradores automáticos, que implicaram em melhorias nas condições das técnicas de aquisição, tratamento e análise de dados, além dos avanços no sensoriamento remoto bem como nas técnicas de representação espacial.

A evolução dos instrumentos e popularização dos registradores automáticos promoveram um salto significativo na compreensão de especificidades do clima urbano, destacando-se as variações em escala de tempo inferior a horária, e o registro de dados durante todo o período do dia, inclusive na madrugara, elemento que permitiu compreender melhor as diferenças termodinâmicas entre o espaço urbano e o entorno rural.

Estando os equipamentos mais acessíveis, ocorreu uma ampliação da produção de dados primários para um número cada vez maior de cidades, seja através da implantação de pontos fixos, seja através de transectos móveis, para a coleta de dados. Nessas condições, de fato, tem se conseguido realmente "adentrar a cidade para tomar-lhe a temperatura" (Monteiro 1990).

Os registradores em pontos fixos, habitualmente registram dados em todas as situações sinóticas, fator esse que tem permitido compreender de maneira mais clara as respostas que o espaço urbano emite em função dos sistemas atmosféricos atuantes. Por outro lado, os transectos móveis, que normalmente são realizados apenas em situações sinóticas estáveis, permitem aprofundar a relação espacial do clima urbano com as características da superfície, ganhando riqueza de detalhes quando se constroem rotas que contemplem unidades espaciais bastante diversificada. Normalmente não se realizam medidas móveis em situações de instabilidade, pois ela tende a equalizar as diferenças térmicas e higrométricas, ou quando a instabilidade ocorre após o início das medidas, ela afeta a confiabilidade dos dados, pois deixa-se de registrar as respostas urbanas e passa-se a registrar os efeitos da instabilidade.

A utilização de dados secundários também se manteve, notadamente nos estudos que relacionam a existência do clima urbano com elementos diversos, como a saúde, a poluição, os eventos extremos etc.

O avanço na produção de dados, por sua vez, gerou um refinamento das técnicas de aquisição, tratamento e análise desses dados. Notadamente se destaca o uso de estatística aplicada ao entendimento do ritmo climático, a ampliação do uso de planilhas eletrônicas, a elaboração de gráficos e mais recentemente o uso de painéis espaço temporais.

O sensoriamento remoto tem proporcionado avanços significativos no estudo do clima urbano, não apenas pela melhoria da resolução espacial das imagens termais, mas também pela aplicação das imagens de alta resolução espacial à compreensão da complexidade do espaço urbano, tais como, na definição do uso e ocupação da terra, na identificação dos materiais construtivos e suas respostas espectrais e no papel da vegetação. Destaca-se também a produção de dados primários no âmbito do sensoriamento remoto, notadamente através da produção de imagens através do uso de Veículos Aéreos não tripulados (VANTs). 
Essa metodologia permite a produção de imagens termais de alta resolução espacial, elemento que pode contribuir com uma melhor compreensão do comportamento térmico da superfície na estruturação do SCU.

A principal vantagem de se utilizar o sensoriamento remoto é sua capacidade de permitir a visualização de temperaturas em grandes áreas; entretanto, é possível obter apenas uma vista panorâmica de temperaturas superficiais, sem que seja viável, por exemplo, se obter as temperaturas de paredes e sob a vegetação (AMORIM, 2015).

A aplicação do sensoriamento remoto aos estudos do clima urbano também tem provocado desdobramentos no âmbito da modelagem espacial (Amorim, et al, 2015). Essa técnica tem sido aplicada por alguns autores no intuito de identificar as potenciais unidades climáticas. Trata-se de mais um esforço de superação das técnicas de interpolação de dados, historicamente utilizadas nos trabalhos de climatologia urbana.

As representações espaciais também demonstraram avanços significativos na geografia como um todo, porém nesse artigo, o objetivo é relacionar as questões ligadas a representação espacial e os estudos do clima urbano.

Parte-se do princípio que qualquer representação gráfica, é mais eficiente na transmissão de informações do que a linguagem escrita. A leitura de um gráfico demanda menos esforço do leitor do que toda a tabela que o deu origem. Quando o objeto da representação gráfica possui um componente espacial, trata-se de uma representação cartográfica. Nesse sentido, entende-se representação espacial, a representação que deriva de elementos que, por sua natureza, apresentam um componente espacial.

Diversas possibilidades estão colocadas para elaboração de representações espaciais no âmbito da climatologia urbana. Os mapas são uma das formas mais utilizadas. Nogueira destaca que:

A representação de dados climáticos na forma de mapas é feita pelo método mais importante utilizado, o isoplético. Deste método derivam os termos isoietas (valores médios de chuva) isóbaras (valores médios de pressão) isotermas (valores médios de temperatura) e outros. O método isoplético também pode ser utilizado para mostrar a duração das condições de tempo em um caso particular. Por exemplo o número de dias em que a temperatura esteve abaixo de $6^{\circ}$ Celsius na região de Fraiburgo (SC). (NOGUEIRA, 2009, p. 163)

Destaca-se que, mesmo sendo o método isoplético o mais utilizado para a representação espacial de dados climáticos, ele é apenas um dos métodos possíveis. A utilização do método isarítmico requer reflexões acerca da interpolação de dados, que passe pela densidade da rede de coleta, da distribuição dos pontos de coleta, do método de interpolação e das características da superfície da região estudada.

Destaca-se, a despeito das excessivas críticas recentes aos mapas isopléticos, que o mapa elaborado através de interpolação de dados, como qualquer outra representação espacial, será uma abstração da realidade, e os resultados serão mais ou menos fiéis a realidade em função de fatores como: densidade da malha de registro de dados, sua distribuição espacial, a escolha das unidades geoambientais diferenciadas, o método utilizado para interpolar os dados, dentre outros.

Acredita-se que o abandono dessa forma de representação espacial não deva acontecer, mas reconhecendo as possibilidades de generalizações espaciais, é recomendado que se faça uso de mais de uma metodologia, cruzando os mapas elaborados através da interpolação com os dados coletados através de transecto móvel e com imagens termais por exemplo, para verificar seu nível de confiabilidade.

Outro elemento importante é o uso da cor nas representações espaciais. O avanço das impressoras coloridas permitiu a disseminação de mapas coloridos, e mais recentemente a divulgação dos trabalhos em meio digital permitiu a reprodução de mapas em vários displays, em diversos tamanhos. Considera-se, de extrema importância a revisão da teoria da cor antes de sua aplicação na construção de representações espaciais. Especialmente no tocante a elaboração das escalas coropléticas e a mistura de cores quentes e cores frias. Cabe aqui ressaltar, que vários autores têm aplicado a teoria da cor às representações espaciais na climatologia urbana, os resultados desses trabalhos poderão apresentar elementos importantes para o equacionamento dessas questões. 


\section{CONSIDERAÇÕES FINAIS}

Inicialmente destaca-que que a maioria dos trabalhos produzidos no Brasil no âmbito da climatologia urbana, faz referência direta ou indireta ao SCU. Esse elemento demonstra a aplicabilidade da proposta, que ainda se apresenta de maneira bastante adequada ao estudo do clima das cidades. Os fundamentos teóricos e metodológicos, estão diretamente ligados a proposta original de Monteiro (1976).

Os avanços identificados estão ligados as questões técnicas, que demonstraram mudanças significativas nos últimos 40 anos. Esses avanços têm permitido uma compreensão mais detalhada da dinâmica do clima urbano, tanto na sua dimensão espacial, como temporal.

Destaca-se as possibilidades futuras da aplicação da modelagem espacial aos estudos do clima urbano, aparentando ser uma importante frente de trabalho que deve ser enfrentada. Associado a ela está a produção de imagens termais de alta resolução espacial através de VANTs. Essa técnica pode permitir avanços significativos para o entendimento das dinâmicas da superfície e sua relação com a atmosfera.

\section{REFERENCIAS}

AMORIM, M.C.C.T. O clima urbano de Presidente Prudente/SP. São Paulo, 2000. 378p. Tese (Doutorado em Geografia) - Faculdade de Filosofia Letras e Ciência Humanas - USP.

AMORIM, M. C. C. T.. Clima urbano: concepções teóricas, metodologias, aplicações e perspectivas. Revista Equador, v. 4, p. 49-66, 2015.

AMORIM, M. C. C. T., DUBREUIL, V.; CARDOSO, R. S., 2015. Modelagem espacial da ilha de calor urbana em Presidente Prudente (SP) - Brasil. Revista Brasileira de Climatologia, 16, 29-45.

ANDRADE, H. O Clima Urbano - natureza, escalas de analises e aplicabilidade. Revista Finisterra, $\mathrm{n}^{\circ}$ 80, 2005, p.67-91

BARROS J.R. Bases Conceituais em Climatologia Geográfica. Revista Mercator, ano 8, nº16, 2009, p.255261

BERTALANFFY, L. Teoria Geral dos Sistemas. Tradução de Francisco M. Guimarães. Petrópolis: Vozes, 1973. 351p.

BERTRAND G. Paisagem e Geografia Física Global: Esboço metodológico. Caderno de Ciências da Terra, São Paulo, v.13 p. 1-13, 1971

BRANDÃO, A. M. de P. M. O clima urbano da cidade do Rio de Janeiro. São Paulo, 1996. 362p. Tese (Doutorado em Geografia Física) - Faculdade de Filosofia Letras e Ciências Humanas, Universidade de São Paulo.

CASSETI, V. Ambiente e Apropriação do Relevo: São Paulo: Contexto, 1991. 147p.

CAVALHEIRO, F. Urbanização e alterações ambientais. In: TAUK, S. M. Análise ambiental: uma visão multidisciplinar. São Paulo: UNESP, FAPESP, SRT, FUNDUNESP, 1991. p. 88-99.

ELY, D. F. Teoria e método da Climatologia geográfica brasileira: uma abordagem sobre seus discursos e práticas. 2006. Tese (Doutorado em Climatologia). UNESP. São Paulo. HANN J. V. Handbuch der Klimatologie. $1^{\mathrm{a}}$.ed. Stuttgart. 1883.

JARDIM, C. H. Proposta de síntese climática a partir do comportamento térmico e higrométrico do ar em áreas urbanas. Tese (Doutorado em Geografia)-Instituto de Geociências da UNICAMP, Campinas, 2007.

LOMBARDO, M. A. Ilha de calor nas metrópoles: o exemplo de São Paulo. São Paulo: Hucitec, 1985. 244p.

MENDONÇA, F. de A. O clima e o planejamento urbano de cidade de porte médio e pequeno: proposição metodológica para estudo e aplicação à cidade de Londrina, PR. São Paulo, 1994. 322P. Tese (Doutorado em Geografia Física) - Faculdade de Filosofia, Letras e Ciências Humanas, Universidade de São Paulo.

MENDONÇA, F.; DANNI-OLIVEIRA, I. M. Climatologia - Noções Básicas e Climas do Brasil. São Paulo: Oficina de Textos, 2007. 208p. 
MONTEIRO C. A. de F. A frente polar Atlântica e as chuvas de inverno na fachada sul-oriental do Brasil: contribuição metodológica à análise rítmica dos tipos de tempo no Brasil. São Paulo: IGEOG/USP, 1969. 68p. (Série Teses e Monografias, 1).

A dinâmica e as chuvas no estado de São Paulo. São Paulo: IGEOG/USP, 1973. 129p. (Estudo geográfico em forma de Atlas).

O clima e a organização do espaço no estado de São Paulo: problemas e perspectivas. São Paulo: IGEOG/USP, 1976. 54p. (Série Teses e Monografias, 28).

Teoria e Clima Urbano. São Paulo, IGEOG/USP, 1976, 181p.

Clima e excepcionalismo: conjecturas sobre o desempenho da atmosfera como fenômeno geográfico. Florianópolis: UFSC, 1991. 241p.

Adentrar a cidade para tomar-lhe a temperatura. Florianópolis. GEOSUL, $\mathrm{n}^{\mathrm{o}} 9-$ Ano $\mathrm{V}-1^{\mathrm{o}}$ semestre de 1990.

MONTEIRO, C. A. de F. e MENDONÇA, F de A. (org). Clima Urbano: São Paulo: Contexto, 2003. 192p.

MOTA, S. Urbanização e Meio Ambiente. Rio de Janeiro: ABES, 1999. 353p.

NOGUEIRA, R.E. Cartografia: representação, comunicação e visualização de dados espaciais. 3. ed. rev. e ampl. Florianópolis: Ed. Da UFSC, 2009.

NUCCI, J. C. Qualidade ambiental e adensamento: um estudo de planejamento da paisagem do distrito de Santa Cecília (MSP). São Paulo, 1996. 229p. Tese (Doutorado em Geografia Física) - Faculdade de Filosofia, Letras e Ciências Humanas, Universidade de São Paulo.

PÁDUA, J.A. Um sopro de destruição: pensamento político e crítica ambiental no Brasil escravista (17861888). Rio de Janeiro. Jorge Zahar Editor, 2004.

PEDELABORDE, P. Introduction a l'etude scientifique du Climat. Paris, Société d/Editión d'Enseignement Supérior, 1970

PITTON, S. E. C. As cidades como indicadores de alterações térmicas. São Paulo, 1997. 272p. Tese (Doutorado em Geografia Física) - Faculdade de Filosofia, Letras e Ciências Humanas, Universidade de São Paulo.

SANT'ANNA NETO, J. L. História da climatologia no Brasil: gênese e paradigmas do clima como fenômeno geográfico. 2001. 169 f. Tese (Livre Docência) - Faculdade de Ciências e Tecnologia, Universidade Estadual Paulista, Presidente Prudente.

SORRE, M. Fundamentos biológicos de la geografía humana: ensayos de una ecología del hombre. Barnacelona. Juventd, 1955. 344p.

Le Climat. In: SORRE, M. Les Fondements de la Géographie Humaine. Paris: Armand Colin, 1951. Chap. 5, p.13-43.

SOTCHAVA, V. O estudo de geossistema. Tradução de MONTEIRO, C. A. de F. e ROMARIZ, D. A. Série Métodos em Questão, 16, São Paulo: IGEOG/USP, 1977.

SPENCER, H. Autobiography. New York. MacMillan, vol. 2. 1904.

ZAVATINI, J. A. A Climatologia Brasileira, o Enfoque Dinâmico e a Noção de Ritmo Climático Desenvolvimento, Progresso e Perspectivas. Boletim Climatologico da FCT/UNESP, Presidente Prudente, v. 1, n.2, p. 11-20, 1996.

A Climatologia Geográfica Brasileira, o Enfoque e a Noção de Ritmo Climático. Revista Geografia. Rio Claro, v. 23, n. 3, p. 5-24, 1998.

O Paradigma da Análise Rítmica e a Climatologia Geográfica Brasileira. Revista Geografia, Rio Claro, v. 25, n. 3, p. 25-43, 2000. 